\title{
Recomendações sobre o uso de equipamentos de proteção individual (EPIs) no ambiente hospitalar e prevenção de transmissão cruzada na COVID-19*
}

\author{
Recommendations for the use of personal protection equipment (PPE) in the hospital and \\ prevention of cross-transmission during COVID-19 pandemic*
}

\author{
MATTE, Darlan Laurício; CACAU, Lucas²; REIS, Luis Felipe da Fonseca³; ASSIS, Mariela \\ Cometki ${ }^{4}$; em nome do Comitê COVID-19 da ASSOBRAFIR*.
}

\begin{abstract}
Resumo
O presente documento tem por objetivo informar sobre os modos de transmissão deste processo infeccioso, a tipologia dos equipamentos de proteção individual (EPIs), suas características, bem como orientar tecnicamente o uso correto destes EPIs no ambiente hospitalar pelos fisioterapeutas, e sobre a prevenção de transmissão cruzada por estes profissionais durante a pandemia de COVID-19. Além disso, estas recomendações nacionais estimulam os fisioterapeutas a se protegerem e utilizarem os EPIs adequadamente. Sabe-se que os fisioterapeutas são imprescindíveis na linha de frente de cuidados ao paciente com COVID-19, e que muitos procedimentos terapêuticos utilizados no contexto hospitalar são fontes dispersoras de aerossóis e assim fornecedores de risco ao ambiente e ao profissional. Desta forma, a proteção destes profissionais durante sua atividade-fim e do seu respectivo local de trabalho é motivo de grande preocupação por parte da ASSOBRAFIR.
\end{abstract}

Palavras-chave: Fisioterapia; Padrão de Cuidado; Biossegurança; COVID-19.

\footnotetext{
* Revisado por membros do ComitêCOVID-19 da ASSOBRAFIR, nomeado por meio do memorando $N^{\circ}$ 003/2020. Esta publicação é uma atualização da Comunicação Oficial "Recomendações sobre o uso de equipamentos de proteção individual (EPIs) no ambiente hospitalar e prevenção de transmissão cruzada na COVID-19 **, chancelada pelo Comitê COVID-19 da ASSOBRAFIR, originalmente escrita pelos mesmos autores e divulgada em 16/04/2020 no endereço eletrônico https://assobrafir.com.br/utilizacaode-equipamentos-de-protecao-individual-epis-durante-a-covid-19\%.

${ }^{1}$ Universidade do Estado de Santa Catarina (UDESC), Florianópolis, SC, Brasil. Email: darlan.matte@udesc.br

DLM - https://orcid.org/0000-0003-4650-3714

${ }^{2}$ Clínica INTERVENT, Aracaju, Sergipe, Brasil. LAPC - https://orcid.org/0000-0002-2676-7854

${ }^{3}$ Programa de Pós-Graduação em Ciências da Reabilitação - UNISUAM, Rio de Janeiro, RJ, Brasil.

LFR - https://orcid.org/0000-0002-6812-6553

${ }^{4}$ Clínica INTERVENT, Aracaju, Sergipe, Brasil. MCA - https://orcid.org/0000-0002-0976-554X
} 


\section{Abstract}

The purpose of this document is to inform about modes of transmission related to COVID-19, the typology of personal protective equipment (PPE) and its characteristics, as well as to provide recommendations about the correct use of PPEs in the hospital by physiotherapists and about the prevention of cross-transmission during the COVID-19 pandemic. In addition, the current recommendations encourage physiotherapists to use PPEs properly in order to protect themselves from being infected. Physiotherapists are essential frontline healthcare workers during the current pandemic, but many interventions used by physiotherapists are considered aerosol generating procedures and therefore are related to high risk of contamination. Thus, the safety of physiotherapists during their duties and the safety of their workplace is a matter of great concern to ASSOBRAFIR.

Keywords: Physiotherapy; Standard of Care; Biosafety; COVID-19.

\section{Objetivo}

O objetivo do presente artigo é oferecer uma visão geral sobre as formas de disseminação e transmissão do SARS-Cov-2 e também sobre as formas de prevenção da contaminação e recursos de proteção individual que deverão ser utilizados pelos fisioterapeutas que estão na linha de frente do enfrentamento da COVID-19 nas instituições hospitalares do país.

\section{Contextualização}

De acordo com a OMS, os profissionais de saúde apresentam maior risco de desenvolver doenças infecciosas comparados a população em geral, devido à maior chance de exposição à carga viral durante o período laboral. Em doenças como a COVID-19, além da transmissão por gotículas e contato, há exposição a procedimentos geradores de aerossóis durante a assistência a esses pacientes. Os profissionais da saúde podem agir como potenciais transmissores assintomáticos, infectando outros pacientes, profissionais e familiares.

A COVID-19 é uma doença com alta infectividade (duas vezes maior que a da gripe), o que significa que uma pessoa doente pode infectar até três pessoas (R0 =2,2; 95\% IC, 1,4-3,9) mesmo com pequena quantidade de material infeccioso ${ }^{1}$.

Existem claras semelhanças filogenéticas e imunológicas entre a epidemia por Coronavírus de 2003 (SARS-CoV-1) e a pandemia atual (SARS-CoV-2/COVID-19) e, por isso, o conhecimento adquirido naquela epidemia pode ser aplicado na atual. Por exemplo, a transmissão do vírus ocorre pelas mesmas formas:

a) respiratória: gotículas e/ou aerossóis (procedimentos específicos);

b) contato com superfícies contaminadas (via mucosas: olhos, nariz, boca);

c) contato com fezes.

Sabe-se também que durante a realização de procedimentos específicos, como o uso da ventilação não invasiva (VNI), oxigenoterapia de alto fluxo, administração de medicação através de nebulização a jato, intubação, aspiração naso ou orotraqual, ressuscitação cardiopulmonar, ventilação com ressuscitador manual, dentre outros procedimentos que geram gotículas e aerossóis, aumenta-se o risco de propagação dos agentes infecciosos e, por isso, as precauções específicas devem ser implementadas desde a admissão de casos suspeitos da COVID-19, até os demais setores de internação. 
O conhecimento das formas de transmissão viabiliza a instituição de estratégias de prevenção contra a disseminação do vírus e proteção de transmissão, destacando-se o uso adequado de EPIs ${ }^{2,3}$.

Não é objetivo deste documento analisar os efeitos das medidas de isolamento social e contingenciamento populacional, as quais jáforam abordadas em outros documentosda ASSOBRAFIR ${ }^{4,5}$. Neste documento, tornamos público o posicionamento da ASSOBRAFIR acerca de estratégias para minimização de transmissão e otimização da segurança no trabalho para o Fisioterapeuta no ambiente hospitalar, atuante com pacientes suspeitos ou diagnosticados com COVID-19.

\section{Orientações e recomendações para prevenção e controle de infecções hospitalares}

Considerando a norma regulamentadora (NR) 6 do Ministério do Trabalho 6 , equipamento de proteção individual (EPI) é "todo dispositivo ou produto, de uso individual, utilizado pelo trabalhador, destinado à proteção de riscos à segurança e saúde no trabalho". A especificação do uso de EPIs no âmbito hospitalar é definida por recomendações da Vigilância Sanitária, mediante o risco de exposição do profissional de saúde ao material biológico, que vão desde precaução padrão, até precauções específicas, como a definida para o atendimento aos pacientes com COVID-19.

Em relação à COVID-19, um estudo analisou 1070 amostras coletadas de diferentes sítios de 205 pacientes e identificou presença do vírus em: lavado broncoalveolar(93\% das amostras), escarro (72\%), swab nasal(63\%), biópsia por fibrobroncoscopia(46\%), swab faríngeo (32\%), fezes (29\%), sangue (1\%) e zero em amostras de urina ${ }^{7}$. A partir disso fica claro que os EPIs devem ser utilizados por toda equipe multidisciplinar, em todos os momentos da assistência aos pacientes suspeitos ou diagnosticados com COVID-19, quando exista possibilidade de contato com esses materiais ${ }^{8}$.

Assim, recomenda-se que toda a equipe deve ser treinada e retreinada sistematicamente no uso adequado de todos os EPIs (colocação e retirada, assim como armazenamento de materiais de reuso, como os respiradores N95 ou PFF2 (peça semifacial filtrante), N99, N100 ou PFF3 e escudos faciais (splash face Shields) 8. Os funcionários com barba devem ser alertados que a presença de barba pode não garantir um bom ajuste de vedação da máscara e diminuir a capacidade de proteção do equipamento?.

\section{EPIs de uso individual a serem utilizados pelos fisioterapeutas em UTIs}

Os fisioterapeutas deverão utilizar os EPIs de acordo com o local de atendimento dentro da unidade hospitalar e a possibilidade ou não de exposição a aerossóis. Os EPIs que analisaremos são principalmente os equipamentos de proteção respiratória (EPR): máscara ou respirador; óculos e escudo facial; capote/avental/touca ou macacão; e luvas, além da forma de colocação e retirada dos mesmos. Esses procedimentos podem ser visualizados no tutorial de paramentação e desparamentação, disponível no site da Escola de Educação Permanente do Hospital das Clínicas - Faculdade de Medicina da Universidade de São Paulo (https://eephcfmusp.org.br/portal/coronavirus\#vtab3 ).

Uso de equipamentos de proteção respiratória (EPR)

Para o fisioterapeuta poder respirar com segurança durante o atendimento de pacientes com COVID-19, recomenda-se preferentemente o uso de respirador (erroneamente chamado de máscara) N95 ou PFF2 (sem válvula de exalação) ou N99 ou PFF3 (sem válvula de exalação) - Figura 1. A 
experiência vivida durante a pandemia em países que apresentaram grande número de infectados e internados simultaneamente, como China e Itália, mostrou que as equipes de saúde adotaram o uso de EPIs para precaução respiratória por aerossóis em todos os atendimentos destinados a pacientes com COVID-19. A proteção com barreira contra aerossóis de forma contínua possibilitou a proteção adequada para qualquer cenário encontrado no âmbito hospitalar. Contudo, no Brasil, diferente de países como Itália e Inglaterra, em virtude da classificação da doença como de transmissão através de gotículas e contato, a orientação tem sido a de uso de máscara cirúrgica (máscara tripla) (Figura 2) durante a assistência aos pacientes em ventilação espontânea, estando o respirador N95 reservado para os procedimentos geradores de aerossóis? ${ }^{7}$.

Figura 1 | Exemplo de equipamentos de proteção respiratória purificador de ar com peça semifacial filtrante (N95 ou PFF2) sem válvula de exalação ${ }^{4}$.

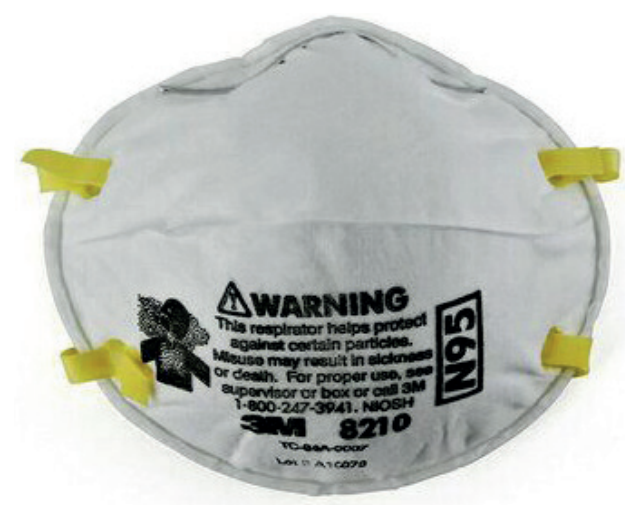

Figura 2 | Exemplo de máscara cirúrgica (máscara de tripla camada) para procedimentos sem geração de aerossóis. 
O uso dos equipamentos de proteção respiratória (EPRs) deveria ocorrer exclusivamente pelo profissional, para atendimento a pacientes com doenças do trato respiratório transmitidas por aerossol, ou procedimentos que envolvam o trato respiratório, no ambiente que esteja acontecendo a formação de aerossóis (intubação; aspiração naso ou orotraqual; ressuscitação cardiopulmonar; ventilação com ressuscitador manual; VNI (principalmente com equipamentos de ramo único e máscara fenestrada); utilização de alguns sistemas de oferta de oxigênio como sistemas de Venturi® e as cânulas nasais de alto fluxo; traqueostomia; extubação traqueal; exame de broncoscopia; coleta de exames em nasofaringe e orofaringe pelos profissionais dos laboratórios de análise clínicas e afins), por conta da sua eficiência de filtragem para partículas menores que 0,3 micrômetros $(\mu \mathrm{m})^{10}$.

Esses respiradores podem ser utilizados para atendimento de mais de um paciente, desde que não ocorra a remoção entre os atendimentos e quando:

- vários pacientes são infectados pelo mesmo patógeno infeccioso;

- estes pacientes estão alocados em uma área específica definida pelo serviço de saúde, para evitar que o profissional de saúde circule em áreas comuns usando o EPI;

- usadas barreiras adicionais que impeçam a contaminação grosseira do EPR, como o uso de escudos de proteção facial (splash face shield). OBS: O uso de máscara cirúrgica por cima da máscara N95 (PFF2) ou N99 (PFF3) foi recentemente desaconselhado em nota técnica da Agência Nacional de Vigilância Sanitária (ANVISA) ${ }^{11}$.

É de conhecimento público que os fabricantes não recomendam a reutilização dos EPRs em seus manuais, e essa é a mesma posição da ASSOBRAFIR. Entretanto, alguns especialistas em infectologia têm recomendado o reuso (uso repetido pela mesma pessoa ao longo de um período, com ou sem reprocessamento) em função da escassez produzida pela pandemia de COVID-19 ao redor do mundo ${ }^{12,13}$. Alguns autores sugerem, inclusive, a possibilidade de descontaminação dos respiradores com peróxido de hidrogênio vaporizado, para que possam ser reutilizados ${ }^{12,13}$, desde que não apresentem sinais de deterioração, sujidade e que passem no teste inicial de utilização e vedação (o qual deve ser realizado com luvas estéreis). Entre os usos, se o respirador for reutilizado, o que em condições normais não seria o recomendado, o mesmo deve ser identificado com o nome do profissional e armazenado em recipientes preferencialmente descartáveis ou laváveis após cada uso (a exemplo dos sacos de papel ou plástico respirável), evitando o contato entre o elástico de fixação e a máscara, sendo mantida acondicionada em local próprio para guarda de EPI, sem que exista contato entre os recipientes das máscaras de cada profissional.

Para guardar o respirador N95 no envelope após a retirada, o profissional deverá evitar tocar a face externa da máscara. Caso seja necessário o toque, fazê-lo após a retirada das luvas e higiene das mãos, ou para acondicionar a máscara no recipiente de armazenamento. Neste momento, para garantir que a parte interna da máscara não seja contaminada, estar atento para não haver toque na área interna da mesma. Para recolocação da máscara devidamente usada, deve-se higienizar as mãos, colocar a máscara, ajustar adequadamente ao rosto para testar a vedação e, ao final do procedimento, higienizar novamente as mãos ${ }^{14,15}$. 


\section{Procedimento padrão para colocação dos EPR (máscaras N95/PFF2 ou superiores) (figura}

3):

1. Segurar o respirador com a pinça nasal próxima à ponta dos dedos, deixando as alças pendentes;

2. Encaixar o respirador sob o queixo;

3. Posicionar um tirante na nuca e o outro sobre a cabeça;

4. Ajustar a pinça nasal e logo após realize o teste de inspiração e expiração para ajustar vazamentos (teste de vedação).

- Este procedimento é determinante para efetividade de filtração e proteção do equipamento. Caso ocorra vazamentos, a proteção por aerossóis é perdida e o usuário estará exposto.

5. Colocar a máscara antes de entrar no quarto/box ou área de atendimento.

Figura 3 | Colocação e adaptação da máscara.
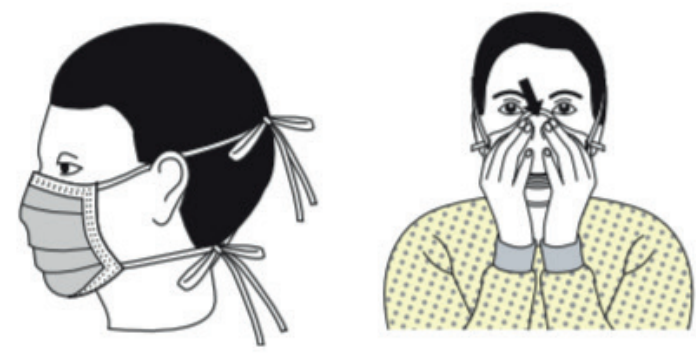

\section{Procedimento padrão para retirada dos EPR (máscaras N95/PFF2 ou superiores) (figura 4):}

1. Jamais toque a parte externa do EPR onde houver risco de contaminação por contato;

2. Segure o elástico inferior;

3. Segure e remova o elástico superior;

4. Remova o EPR pelos elásticos, sem tocar sua parte frontal externa, descartando-a. A retirada deve ocorrer após fechar a porta, estando fora do quarto/box, no corredor. Nos casos de unidades exclusivas para COVID-19, as máscaras devem ser retiradas apenas no fim do turno de trabalho ou em caso de saída do setor.

5. Descarte a máscara quando estiver com sujidade visível, danificada ou houver dificuldade para respirar (saturação da máscara). 
Figura 4 | Retirada e descarte da máscara.
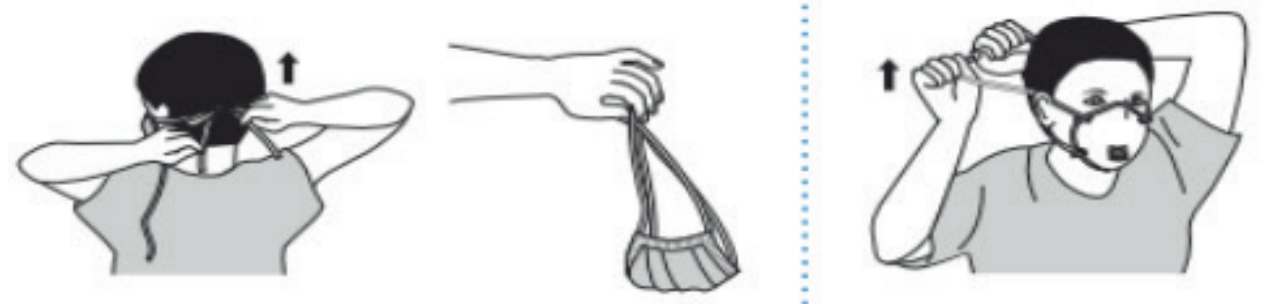

\section{Recomendações quanto ao uso de luvas por profissionais de saúde}

O uso de luvas de procedimentos não cirúrgicos, no contexto da epidemia da COVID-19, é para qualquer contato com o paciente ou seu entorno (precaução de contato) (ver figura 5). Quando o procedimento a ser realizado no paciente exigir técnica asséptica, devem ser utilizadas luvas estéreis (de procedimento cirúrgico) $)^{14,15}$.

Figura 5 | Momentos de uso de luvas de procedimento pelos profissionais de saúde.

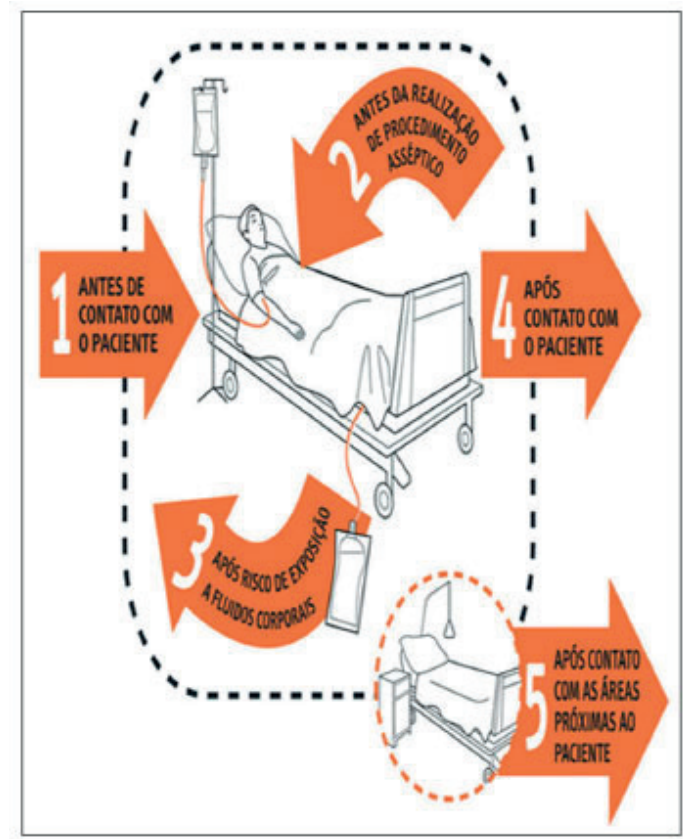

De forma simplificada, as luvas de procedimento devem ser utilizadas pelo fisioterapeuta em todo e qualquer atendimento a pacientes que estão com suspeita ou diagnóstico de COVID-19. Elas devem ser colocadas imediatamente antes da assistência ao paciente e após a higienização das mãos, assim como devem ser removidas imediatamente após a assistência ao paciente, ainda dentro do quarto, UTI ou área de isolamento. Ao término do atendimento, devem ser descartadas como resíduo infectante para os pacientes em precaução de contato ou quando sujas com grande quantidade de material biológico. Após a retirada e o descarte da luva, o profissional deverá higienizar as mãos (figuras 6 e 7). 
Figura 6 | Higienização das Mãos com preparações alcoólicas (Gel ou Solução a 70\% com 1-3\% de Glicerina).

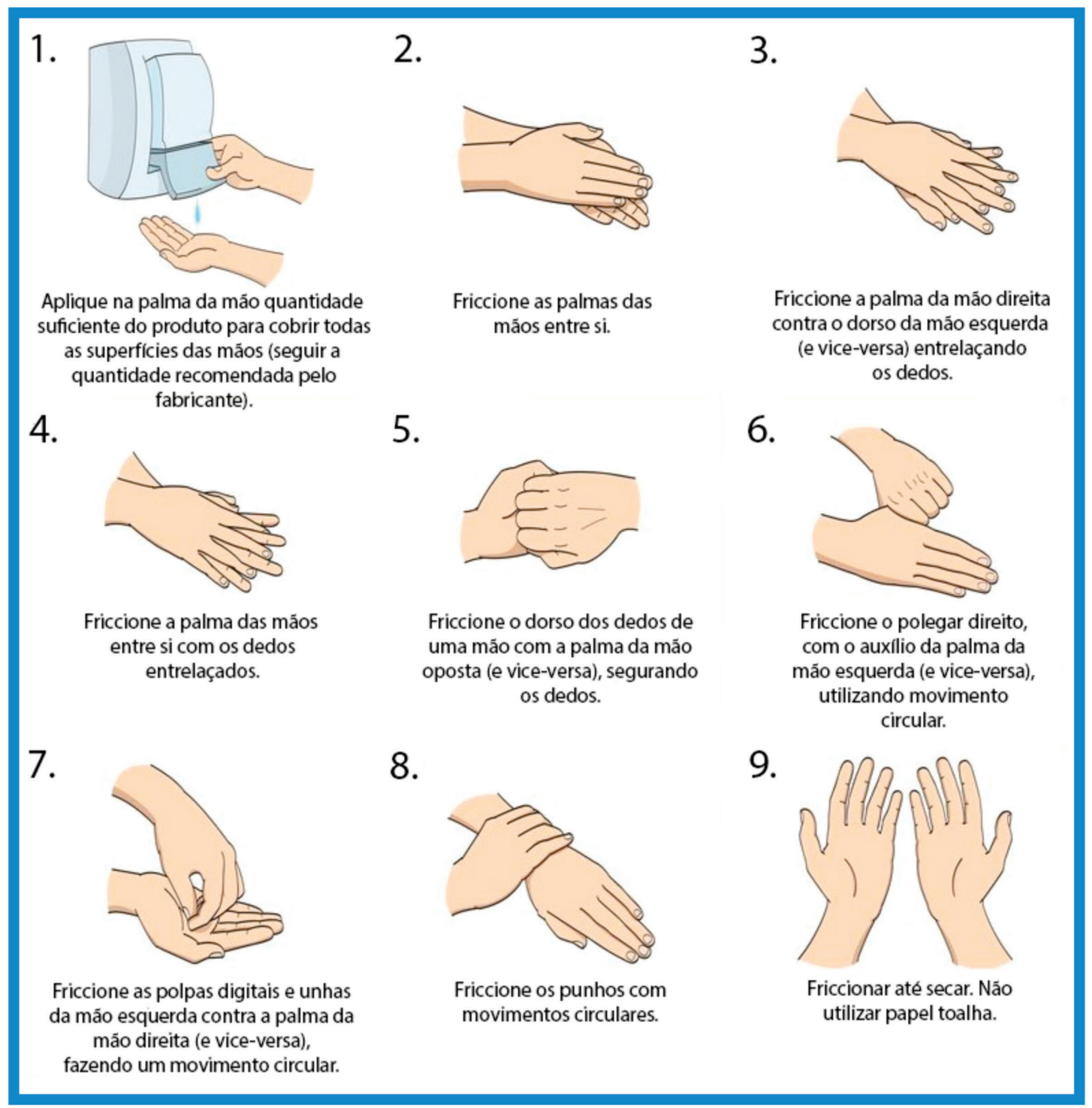


Figura 7 | Higienização simples das mãos das mãos (água e sabão).

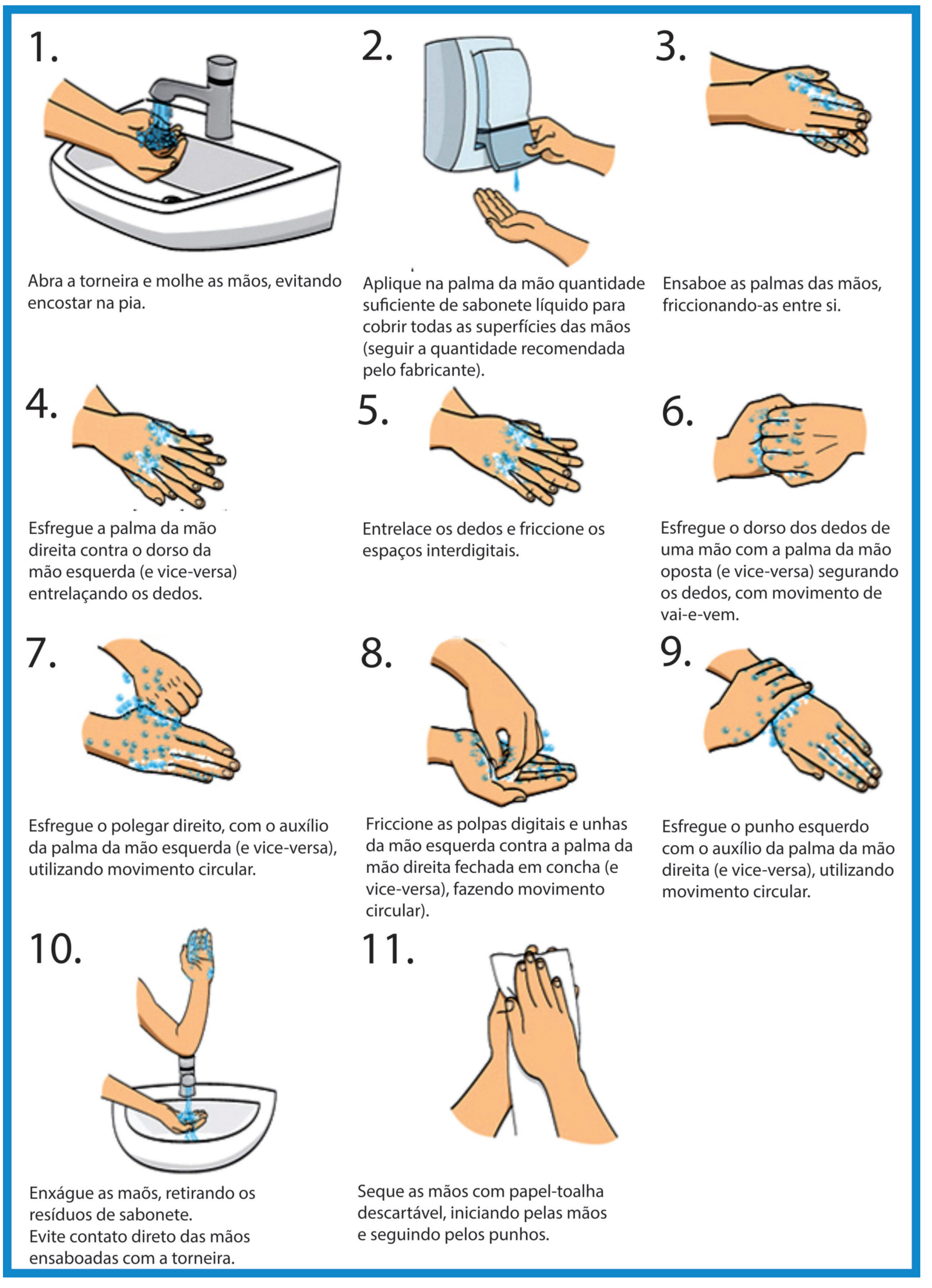


Em relação à prevenção de contaminação por contato, algumas orientações devem ser seguidas:

1. Nunca toque desnecessariamente superfícies e materiais (telefones, maçanetas, portas e outros), enquanto estiver com luvas;

2. Não lavar ou usar novamente o mesmo par de luvas (as luvas nunca devem ser reutilizadas);

3. Não é recomendado a utilização de duas luvas para o atendimento dos pacientes, pois aparentemente isso não garante mais segurança à assistência;

4. Realizar a higiene das mãos imediatamente após a retirada das luvas;

5. Atentar para a técnica correta de colocação e remoção de luvas a fim de evitar a contaminação das mãos, como ilustrado nas Figuras 8 e 9, respectivamente:

- Retire as luvas puxando a primeira pelo lado externo do punho com os dedos da mão oposta (Figura 8);

- Segure a luva removida com a outra mão enluvada;

- Toque a parte interna do punho da mão enluvada com o dedo indicador oposto (sem luvas) e retire a outra luva.

Figura 8 | Procedimento de colocação das luvas.

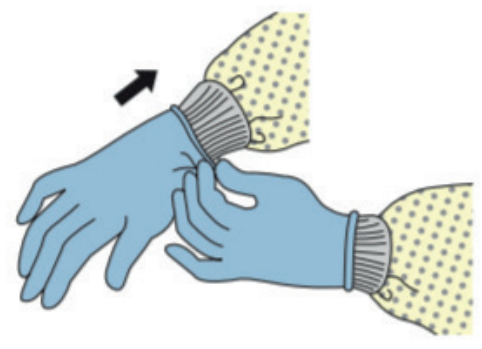

Figura 9 | Procedimento de retirada das luvas.
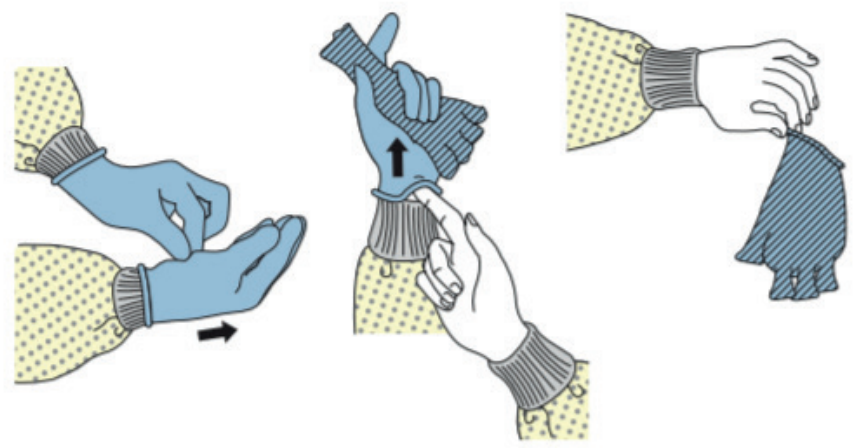


\section{Recomendações do uso do protetor ocular, protetor ocular de sobrepor ou escudo protetor facial (face shield ou splash face shield)}

Os óculos de proteção ou escudos protetores faciais devem ser de uso exclusivo do profissional e utilizados quando houver risco de exposição a respingos de sangue, secreções corporais, incluindo escarro, e excreções. A sequência e a forma de instalação e retirada devem seguir as figuras 10 e 11 . Após o seu uso, deve ser realizada a limpeza com água e sabão e posterior desinfecção com álcool líquido $70 \%$, hipoclorito de sódio, ou outro desinfetante recomendado pelo fabricante ${ }^{14,15}$.

Figura 10 | Procedimento de colocação dos protetores de face.
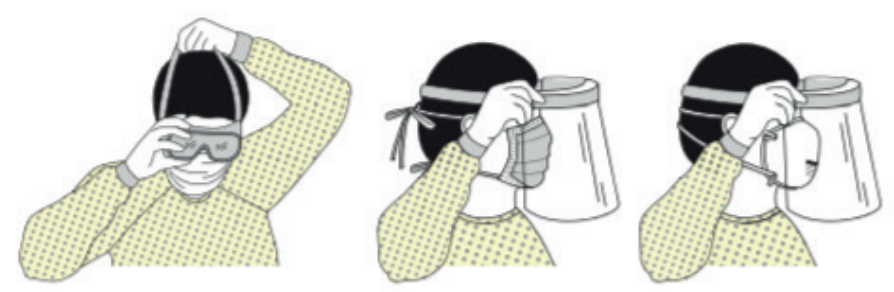

Figura 11 | Procedimento de retirada dos protetores de face.

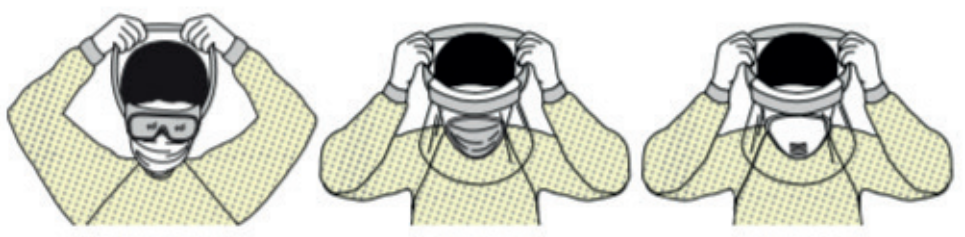

\section{Uso do capote ou avental}

Este deve ser de gramatura mínima de $50 \mathrm{~g} / \mathrm{m} 2$, de boa qualidade, atóxico, hidro/hemorrepelente, hipoalérgico, com baixo desprendimento de partículas e resistente. Deve ser de mangas longas, com punhos de malha ou elástico e abertura posterior para evitar a contaminação da pele e da roupa do profissional. A figura 12 ilustra o procedimento de instalação, enquanto a figura 13 demonstra o processo de retirada. A remoção e o descarte do capote ou avental deve ser realizada após a realização do procedimento e antes de sair do quarto do paciente ou da área de assistência, sendo feita em local apropriado para resíduo infectante. Após a remoção do capote, deve-se realizar a higiene das mãos para evitar a contaminação.

É importante salientar que a maior parte dos profissionais se contaminam no momento da retirada dos EPIs, pela presença de vírus nesse material, principalmente capote/avental ou macacão, que deve ser retirado de forma lenta e cuidadosa, para minimizar a chance de desprendimento do vírus que pode ficar na superfície e possibilitar a contaminação do ambiente e do profissional ${ }^{14,15}$. 
Figura 12 | Procedimento de colocação dos aventais.
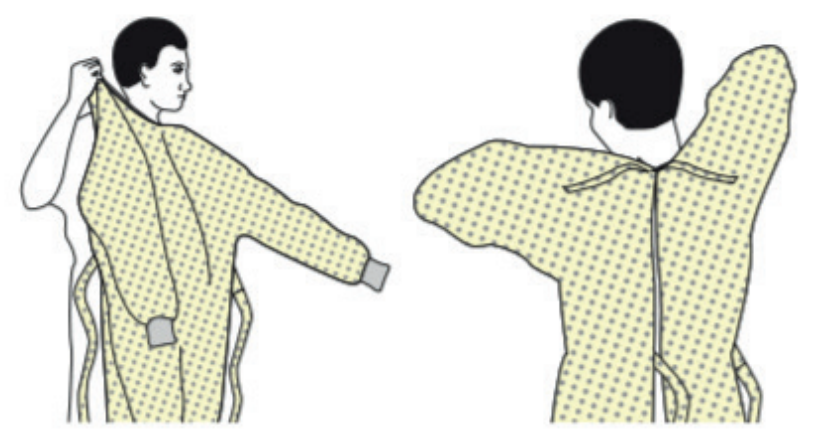

Figura 13 | Procedimento de retirada dos aventais.
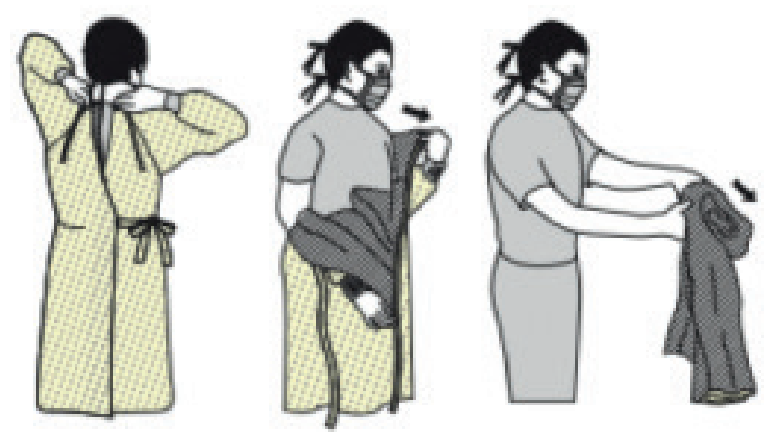

\section{Uso de sapatos fechados}

Os sapatos utilizados nesses ambientes devem ser impermeáveis a líquidos, fechados e que possibilitem higienização.

O uso de propés ou sapatos tipo “Crocs®” não garante a segurança dos pés, devido a possibilidade de materiais biológicos entrarem em contato com a pele do profissional.

\section{Outros EPIs}

O uso do gorro, toca ou balaclava, cobrindo a cabeça, ouvidos e pescoço, é recomendado quando houver produção de gotículas e principalmente aerossol. Essa é uma medida que pode variar entre as instituições.

\section{Demais objetos utilizados no ambiente de trabalho}

Objetos pessoais utilizados no ambiente de atendimento aos pacientes podem ser vetores de contaminação. Portanto, minimize o número de objetos pessoais no local de trabalho. $\mathrm{O}$ uso de adornos (brincos, relógios, anéis, colares) é proibido no ambiente hospitalar. Lembre-se que o crachá pendurado no pescoço é um objeto que favorece muito a contaminação. 


\section{Locais de Atendimento nas Unidades Hospitalares}

Para todos os pacientes suspeitos ou diagnosticados com COVID-19 e onde exista possibilidade de geração de aerossóis, o ideal é que o atendimento seja realizado em salas de classe $\mathbf{N}$.

- Salas de classe N (isolamento com pressão negativa)

As salas de classe $\mathbf{N}$ possuem um sistema de exaustão que força o ar a sair do ambiente, fazendo cerca de 12 trocas de ar por hora. Essas salas normalmente têm uma antecâmara funcional para vestimenta e retirada de EPIs. Mesmo com a renovação do ar a cada pequeno espaço de tempo, as precauções para colocação e retirada dos EPIs e uso de respiradores N95 ainda são necessárias. No entanto, pode haver variações locais nos diferentes serviços, podendo também ser recomendada a remoção do avental e luvas no quarto do paciente e, em seguida, a remoção do escudo facial / óculos e máscara fora do quarto do paciente.

\section{- Salas da classe S}

Essas salas podem ser utilizadas para isolar pacientes capazes de transmitir infecção por gotículas ou contato e não possuem capacidade de pressão negativa. Recomenda-se que o paciente com COVID-19 seja tratado em um quarto individual de pressão negativa classe N. Se os quartos da classe $\mathrm{N}$ não estiverem disponíveis, a preferência deve ser pelos quartos individuais da classe $\mathrm{S}$, com áreas limpas demarcadas para colocação e retirada de EPIs. Uma vez que todas as classes $\mathrm{N} \mathrm{e}$ os quartos individuais da classe $S$ estão esgotados, os pacientes precisarão ser alocados em áreas fisicamente separadas das áreas que contenham pacientes sem COVID-19. Para área aberta de coorte de UTI ou enfermaria com um ou mais pacientes com COVID-19, recomenda-se que em toda a área sejam exigidas EPIs para precauções de aerossóis.

Em relação a higiene do ambiente, não se recomenda a utilização de aparelhos de ar condicionado do tipo split nas unidades de tratamento do COVID-19, pois estes turbilhonam o ar do local, mantendo os vírus por mais tempo em flutuação (suspensão), além de não renovar e filtrar o ar de forma adequada (circulação fechada). É recomendado que os serviços que dispunham de ar condicionado central utilizem em suas máquinas filtros de alta eficiência e revisem seu funcionamento para evitar a disseminação da contaminação para outros ambientes do hospital ${ }^{16}$. 


\section{Sequência para Colocação e Retirada dos EPIS}

\section{Sequência de Colocação: (Menor risco de contaminação)}

1. Higienização das mãos

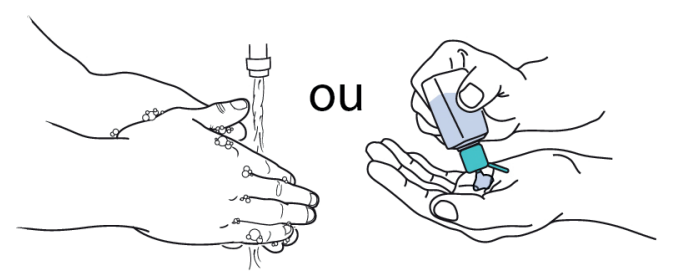

2. Coloque o macacão, avental ou capote:
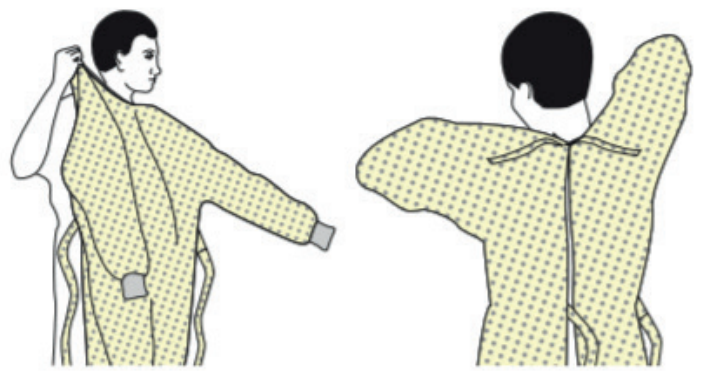

3. Coloque o respirador e teste a vedação do equipamento
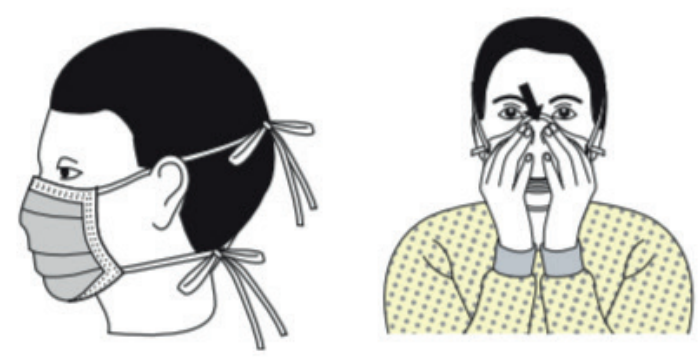

4. Coloque os óculos, o escudo facial (splash face shield) e o gorro/touca
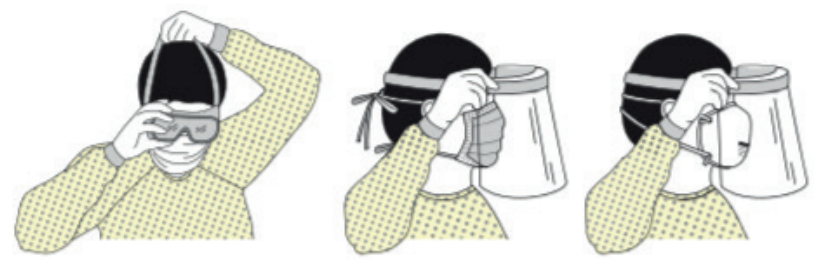
5. Coloque as luvas

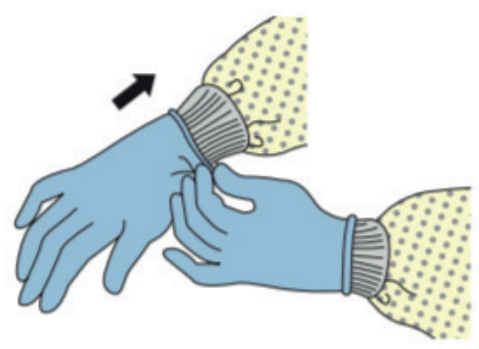

\section{Sequência de Retirada: (Maior risco de contaminação)}

1. Retire as luvas

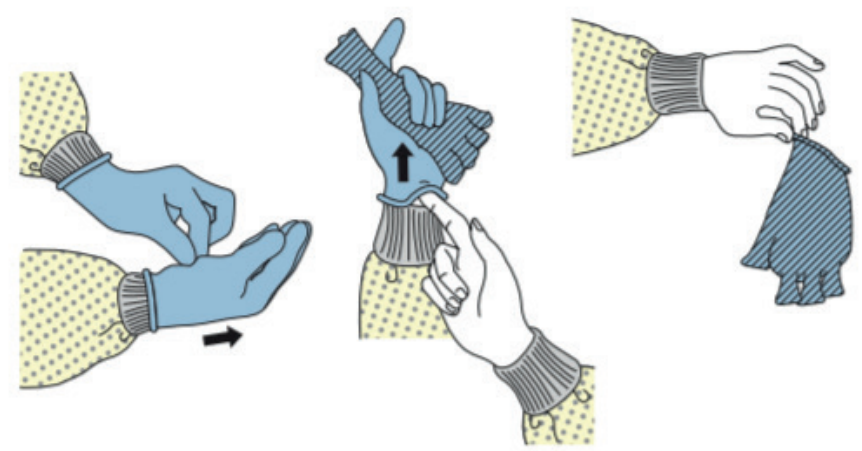

2. Higienize as mãos

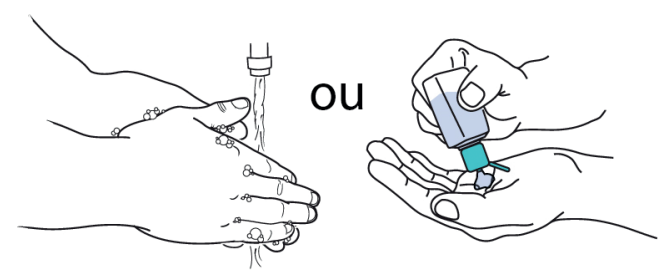

3. Retire a touca e após retire e higienize a splash face shield e os óculos

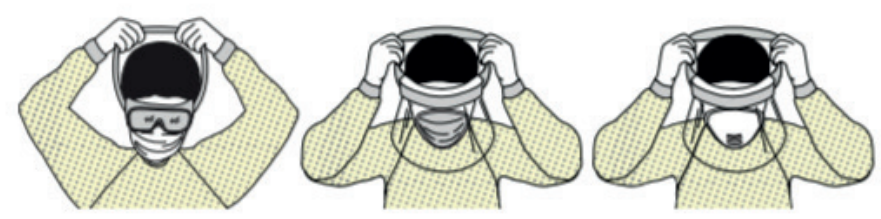


4. Retire o capote/avental/macacão

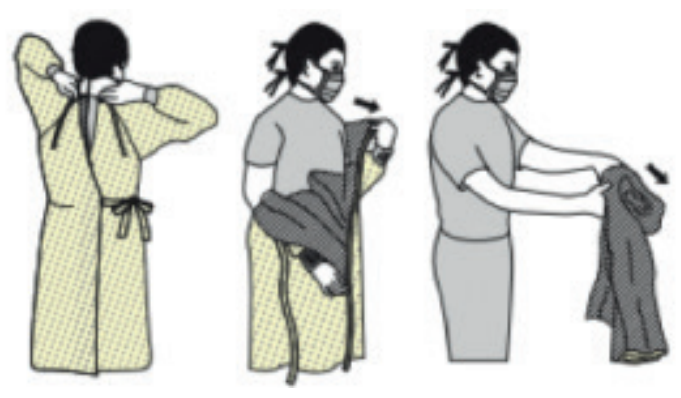

5. Higienize as mãos

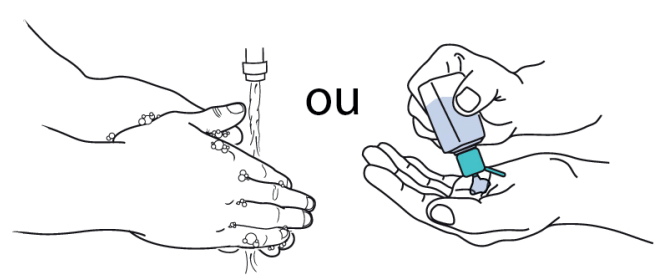

6. Retire a máscara ou o respirador
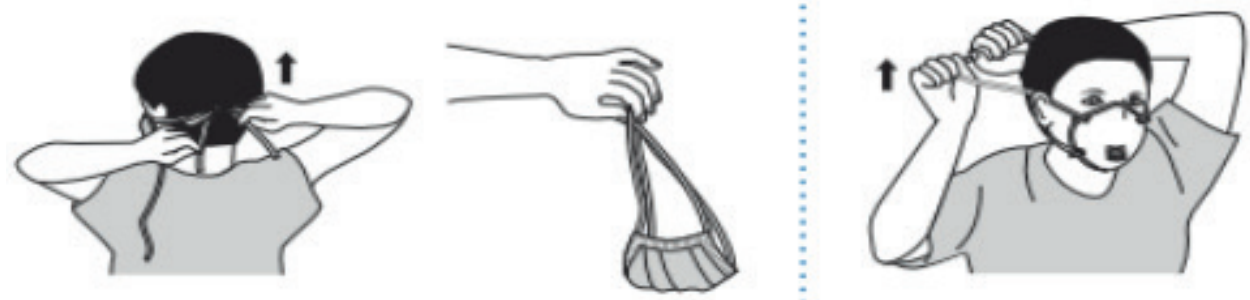

7. Higienize as mãos

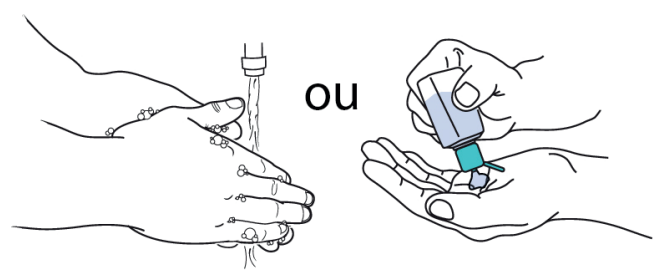

8. Por fim, recomenda-se tomar banho com água e sabão no local de trabalho para em seguida colocar roupa de convívio social, ou então, assim que chegar em casa. 


\section{Considerações Finais}

A contaminação de profissionais da saúde continua frequente em países que passaram ou estão passando pela pandemia da COVID-19. A contaminação de um profissional de saúde é muito danosa a todo o sistema. Além do problema de saúde que o profissional adquire e o risco de morte que corre, deixa de estar na linha de frente no combate à doença, desfalcando as equipes, exigindo substituição, podendo ser um potencial contaminante para os demais pacientes, colegas de trabalho e seus familiares. Portanto, evitar a contaminação dos profissionais de saúde é medida indispensável.

É imperativo que os Fisioterapeutas atentem para as orientações descritas neste documento, fazendo-se cumprir em sua totalidade, para impedir a disseminação da transmissão viral responsável pela COVID-19 e preservar a própria saúde e dos demais profissionais envolvidos no combate à pandemia. Recomenda-se que EPIs de qualidade e em quantidade suficiente sejam disponibilizados pelos empregadores para todos os profissionais envolvidos no combate à pandemia.

\section{Referências}

1. Li Q, Guan X, Wu P, Wang X, Zhou L, Tong Y, et al. Early transmission dynamics in Wuhan, China, of novel coronavirus-infected pneumonia. N Engl J Med. 2020 Mar 26;382(13):1199-1207. doi: 10.1056/ NEJMoa2001316.

2. Health Protection Scotland. Rapid Review: Infection Prevention and Control Guidelines for the Mangement of COVID-19 [Internet]. Glasgow: Health Protection Scotland; 2020. Available from: https://www.ecdc.europa.eu/sites/default/files/documents/COVID-19-infection-prevention-andcontrol-healthcare-settings-march-2020.pdf

3. Offeddu V, Yung CF, Low MSF, Tam CC. Effectiveness of Masks and Respirators Against Respiratory Infections in Healthcare Workers: A Systematic Review and Meta-Analysis. Clin Infect Dis. 2017 Nov 13;65(11):1934-1942. doi: 10.1093/cid/cix681.

4. Matte DL, Andrade FMD, Martins JA. O fisioterapeuta e sua relação com o novo betacoronavirus 2019 (2019-nCoV). São Paulo: ASSOBRAFIR; 2020 [cited 2020 Mar 27]. Available from: https:// assobrafir.com.br/wp-content/uploads/2020/01/ASSOBRAFIR BETACORONAVIRUS-2019 v.4.pdf.

5. Martinez BP, Maciel F, Martins JA, Matte DL, Marlus Karsten M. COVID-19: Papel do Fisioterapeuta em diferentes cenários de atuação. São Paulo: ASSOBRAFIR; 2020 [cited 2020 Mar 27]. Available from: https://assobrafir.com.br/wp-content/uploads/2020/03/Papel-do-Fisioterapeuta COVID-19 jus-1. pdf

6. MTB. NR 6 Equipamentos de proteção individual [Internet]. Brasília: MTB; 2020. Available from: http://trabalho.gov.br/seguranca-e-saude-no-trabalho/normatizacao/normas-regulamentadoras.

7. van Doremalen N, Bushmaker T, Morris DH, Holbrook MG, Gamble A, Williamson BN, et. al. Aerosol and Surface Stability of SARS-CoV-2 as Compared with SARS-CoV-1. N Engl J Med. 2020 Apr 16;382(16):1564-1567. doi: 10.1056/NEJMc2004973. Epub 2020 Mar 17.

8. WHO. Rational use of personal protective equipment for coronavirus disease (COVID-19): Interim guidance, 27 Feb 2020. Geneva: World Health Organization; 2020. Available from: https:// apps.who.int/iris/bitstream/handle/10665/331215/WHO-2019-nCov-IPCPPE use-2020.1-eng. pdf? sequence $=1$ \&isAllowed $=\mathrm{y}$

9. NHMRC. Australian Guidelines for the Prevention and Control of Infection in Healthcare 2019 
[Internet]. Canberra: National Health and Medical Research Council; 2020. Available from: https:// www.nhmrc.gov.au/about-us/publications/australian-guidelines-prevention-and-control-infectionhealthcare-2019

10. Thomas P, Baldwin C, Bissett B, Boden I, Gosselink R, Granger CL, et al. Physiotherapy management for COVID-19 in the acute hospital setting: clinical practice recommendations. J Physiother. 2020 Apr;66(2):73-82. doi: 10.1016/j.jphys.2020.03.011. Epub 2020 Mar 30.

11. ANVISA. Nota Técnica GVIMS/GGTES/ANVISA no 04/2020. Orientações para serviços de saúde: medidas de prevenção e controle que devem ser adotadas durante a assistência aos casos suspeitos ou confirmados de infecção pelo novo coronavírus (SARS-CoV-2) [Internet]. Brasília: Agência Nacional de Vigilância Sanitária; 2020 [atualizada 2020 Mar 31]. Available from: http://portal.anvisa.gov.br/ documents/33852/271858/Nota+T\%C3\%A9cnica+n+04-2020+GVIMS-GGTES-ANVISA/ab5986603de4-4f14-8e6f-b9341c196b28

12. SBPT. Recomendações da SBPT sobre o uso de máscaras no âmbito da COVID-19 [Internet]. Brasília: Sociedade Brasileira de Pneumologia e Tisiologia; 2020. Available from: https://sbpt.org.br/ portal/uso-mascaras-covid19-sbpt/

13. Bauchner H, Fontanarosa PB, Livingston EH. Conserving Supply of Personal Protective Equipment-A Call for Ideas. JAMA. 2020 Mar 20. doi: 10.1001/jama.2020.4770. Online ahead of print. 14. WHO. Report of the WHO-China Joint Commission on Coronavirus disease 2019 (COVID-19) [Internet]. Geneva: World Health Organization; $2020 \mathrm{Feb}$ 16-24. Available from: https://www.who.int/ docs/default-source/coronaviruse/who-china-joint-mission-on-covid-19-final-report.pdf

15. WHO. Q\&A on infection prevention and control for health care workers caring for patients with suspected or confirmed 2019-nCoV. Geneva: World Health Organization; 2020 Mar 31. Available from: https://www.who.int/news-room/q-a-detail/q-a-on-infection-prevention-and-control-for-healthcare-workers-caring-for-patients-with-suspected-or-confirmed-2019-ncov

16. WHO. Natural ventilation for infection control in health-care settings [Internet]. Geneva: World Health Organization; 2009. Available from: http://www.who.int/water sanitation health/publications/ natural ventilation/en/index.html

Submissão em: 22/06/2020

Aceito em: 15/07/2020 